\title{
FAMILIAL LEUCODYSTROPHY
}

\author{
BY \\ P. L. MASTERS, W. B. MACDONALD, M. M. P. RYAN, and J. N. CUMINGS \\ From the Princess Margaret Hospital for Children, Perth, Western Australia, and \\ the Department of Chemical Pathology, The Institute of Neurology, Queen Square, London
}

(RECEIVED FOR PUBLICATION DECEMBER 3, 1963)

Up to the present the classification of diffuse leucodystrophies in childhood has been based on histology. During recent years several workers have been undertaking chemical analyses of the brains from children whose diseases came into the general group of leucodystrophies, and have found chemical patterns which usually correlate with the histological findings (Edgar, 1957; Jatzkewitz, 1960; Cumings, 1962). The four children in two families whose case histories are reported here are of interest because they showed clinical features, a familial incidence, and chemical changes in the brain consistent with a leucodystrophy, in the absence of specific histological features.

\section{Case Reports}

Case 1. A girl born on October 22, 1953, birth weight $2.3 \mathrm{~kg}$., was the fifth child in the family, the four older sibs being normal. Pregnancy and labour were uneventful. She was fed with cows' milk mixture from birth and was difficult to feed, underweight, and inclined to vomit from an early age. Although not abnormally late in walking she was unsteady on her feet and tended to fall easily.

She was brought for medical advice at the age of 3 years and 2 months because of vomiting for three days. Hard faecal masses were felt in the left iliac fossa. She weighed $9.6 \mathrm{~kg}$. and was sufficiently dehydrated to require intravenous fluids. Two days later she had several epileptiform fits and vomited altered blood, but these symptoms did not persist. All investigations were negative, and encephalitis was considered to be the most likely diagnosis.

At the age of 3 years and 9 months she was readmitted to hospital because of vomiting, fever, and dehydration. Her weight was then only $9 \cdot 1 \mathrm{~kg}$., and investigations were again negative. She was well enough to leave hospital after a week, but continued to have attacks of vomiting.

At the age of 5 years 5 months she came into hospital because her fits had recurred. She was weak, apathetic, and grossly emaciated, her weight being the same as at her last admission. She had constant twitching movements of the right arm and there were faecal masses in the abdomen. Several attacks of vomiting and colicky abdominal pain, with abdominal distension, constipation, and dehydration, followed. She was given intravenous fluids and numerous enemata for removal of scybala. A barium enema showed a very dilated large bowel without evidence of mechanical obstruction. This was considered by the radiologist to indicate stasis due to defective motor function. She died unexpectedly in hospital aged 5 years 7 months.

At mecropsy she was undersized, emaciated and grossly underweight (Table 1). The brain, weighing 1,137 g., was slightly small for the age, but appeared normally formed. The heart, weighing $61 \mathrm{~g}$., and great vessels were normal anatomically. There were several small yellow plaques on the intimal surface of the aorta close to the valve and on the adjacent membranous interventricular septum. The trachea and main bronchi were filled with thick yellowish pus and showed slight mucosal injection. The lungs, weighing $281 \mathrm{~g}$., showed considerable generalized oedema and collapse of the posterior parts of the lower lobes. Histologically there was purulent bronchiolitis and early bronchopneumonia. Cultures $\mathrm{cf}$ trachea and lungs yielded Pseudomonas pyocyanea.

The jejunum was moderately distended and there was an abrupt reduction in calibre about half-way along the small intestine without obvious cause. The ileum contained several small scybala, and portions of it were slightly distended. The caecum, transverse colon, and descending colon were distended with large scybala, while the ascending colon, sigmoid, and rectum were small in calibre and empty.

The liver, weighing $429 \mathrm{~g}$., showed congestion and fatty change. The spleen, weighing $13 \mathrm{~g}$., was smaller than expected and normal on slicing. The adrenals, weighing $5 \mathrm{~g}$., were normal and the other organs were normal.

The diagnosis at necropsy was bronchopneumonia complicating cerebral degeneration. There was no family history of a similar disorder, and the parents were not blood relatives.

Case 2. Born July 24, 1958 , birth weight $2.75 \mathrm{~kg}$., this boy was the next born sib to Case 1 . There was a normal pregnancy and labour. Like his sister he was difficult to feed and inclined to vomit from an early age. 
TABLE 1

BODY WEIGHTS, BODY LENGTHS, AND BRAIN WEIGHTS AT NECROPSY

\begin{tabular}{|c|c|c|c|c|c|c|c|}
\hline \multirow{2}{*}{ Case } & \multirow{2}{*}{ Age } & \multicolumn{2}{|c|}{ Body Weight } & \multicolumn{2}{|c|}{ Body Length } & \multicolumn{2}{|c|}{ Brain Weight } \\
\hline & & Actual & $\begin{array}{c}\text { Age } \\
\text { Equivalent }\end{array}$ & Actual & $\begin{array}{c}\text { Age } \\
\text { Equivalent }\end{array}$ & Actual & $\begin{array}{c}\text { Age } \\
\text { Equivalent }\end{array}$ \\
\hline 1 & 5 yr. $6 \mathrm{mth}$. & $9 \cdot 1 \mathrm{~kg}$ & $9 \mathrm{mth}$ & $102 \mathrm{~cm}$ & $4 \mathrm{yr}$. & $1.176 \mathrm{~g}$ & 3 yr. \\
\hline 2 & 2 yr. $10 \mathrm{mth}$ & $7 \cdot 5 \mathrm{~kg}$ & $6 \mathrm{mth}$. & $80 \mathrm{~cm}$ & $1 \mathrm{yr} .6 \mathrm{mth}$. & $836 \mathrm{~g}$ & $8 \mathrm{mth}$. \\
\hline 3 & 3 yr. $4 \mathrm{mth}$. & $5.9 \mathrm{~kg}$. & 3 mth. & $72 \mathrm{~cm}$ & $10 \mathrm{mth}$. & $1,037 \mathrm{~g}$. & $1 \mathrm{yr} .6 \mathrm{mth}$. \\
\hline 4 & 1 yr. $7 \mathrm{mth}$. & $6 \cdot 3 \mathrm{~kg}$ & $4 \mathrm{mth}$. & $69 \mathrm{~cm}$ & $8 \mathrm{mth}$. & $872 \mathrm{~g}$. & $9 \mathrm{mth}$. \\
\hline
\end{tabular}

When 5 weeks old he was admitted to hospital for an attack of paroxysmal tachycardia which subsided rapidly after digoxin was given. An electrocardiogram suggested a partial right bundle-branch block.

When 10 months old he was admitted for suspected backwardness. Although average in length he weighed only $7 \cdot 7 \mathrm{~kg}$. (third percentile for age) and could not sit without support. Nevertheless he did not seem malnourished, was normally hydrated, and appeared contented. His facies were unusual, with large low-slung ears and large mouth.

When 2 years old he began to have convulsions and attacks of vomiting, colic, and constipation. At $2 \frac{1}{2}$ years he was admitted to hospital following a convulsion. He was pale, irritable, and hypotonic, with a very distended abdomen and scybala in the descending colon. He was obviously retarded physically and mentally, and weighed only $8.96 \mathrm{~kg}$.

After his return home the fits became more frequent, usually involving the right side of the face, right arm, and left leg. When he was 2 years and 10 months he was readmitted to hospital in status epilepticus and died a few hours afterwards.

At necropsy he was undersized and grossly underweight (Table 1), with a small cranium (occipito-frontal diameter $44.5 \mathrm{~cm}$.).

The brain, weighing $836 \mathrm{~g}$., was small for the age, but the medulla, pons, and cerebellum, weighing $100 \mathrm{~g}$., were relatively larger. There was slight widening of the sulci of the cerebral hemispheres, and slicing of the fixed brain showed some reduction in the central white matter.

The heart, weighing $113 \mathrm{~g}$., was overweight, even for the age, and all chambers were distended with blood. There were no anatomical abnormalities of the heart or great vessels and the cause of the hypertrophy was not clear. There was a small yellow plaque on the intima of the proximal aorta. The trachea was filled with frothy mucus and milk curds but showed no mucosal injection. Culture yielded profuse Haemophilus influenzae and Esch. coli. The lungs, weighing $183 \mathrm{~g}$., showed marked generalized oedema but no consolidation. The branches of the pulmonary arteries were unusually prominent and empty. Culture was sterile. Histologically there was bronchitis, lobular collapse, and emphysema.

The intestines showed distension of the terminal ileum and caecum with gas and soft faecal pellets, and distension of the lower sigmoid and rectum with scybala. The liver, weighing $369 \mathrm{~g}$., was slightly congested. The spleen, weighing $19 \mathrm{~g}$., was small and showed slight hyperplasia of the follicles. The thymus, weighing $1 \mathrm{~g}$., was atrophic. The adrenals, weighing $4 \cdot 3 \mathrm{~g}$., were normal, and the other organs were normal.

The diagnosis at necropsy was congestive heart failure associated with cardiomegaly, and microcephaly.

Case 3. Born on February 7, 1958, birth weight $2 \cdot 67$ kg., this boy was the second in the family, having a normal brother two years older. The pregnancy was normal and ended at 38 weeks with an uncomplicated breech delivery.

During the first six months of life he was well apart from recurrent purulent nasal discharge and occasional vomiting. His mother then became concerned about his slow progress and noticed prominence of the veins on the sides of his scalp. When he was 7 months old she brought him for medical advice because of constipation for $\mathbf{4 8}$ hours and severe vomiting for 24 hours. On examination he was a toxic, dehydrated baby showing gross abdominal distension and faecal vomiting. The skull was normal in size but the shape was unusual, being square anteriorly and flattened over the occiput. Prominent but not congested veins were seen over the temporal and parietal areas of the scalp. He had an unusual elfin face, with a flattened nose, a large forehead and pointed ears, and his digits were unusually long. His weight, $4.86 \mathrm{~kg}$., was below the third percentile for his age. He was just able to support his head, could not sit up, and appeared retarded mentally.

Intestinal obstruction was diagnosed and laparotomy revealed general peritonitis, a grossly dilated large bowel containing hard faeces and a small segment of gangrenous ileum about three feet from the ileocaecal junction. The gangrenous segment, thought possibly to be due to an intra-abdominal hernia, was resected and an end-to-end anastomosis performed. Sections of the segment showed normal myenteric plexuses.

The child returned to hospital many times for treatment of respiratory infections, sometimes associated with convulsions, and for several attacks of constipation with vomiting, dehydration, and abdominal distension. He made no further mental or physical progress, and during the last eight months of life there was mental and physical deterioration. He did not have spontaneous bowel actions and required institutional care.

The clinical diagnosis when he died aged 3 years and 4 months was cerebral degeneration of undetermined type. There was no family history of a similar disorder, and the parents were not blood relatives. 
At necropsy the body was undersized, underweight, and emaciated (Table 1), with the cranial and facial appearances already described.

The brain, weighing 1,037 g., was slightly small for the age. The medulla, pons, and cerebellum, weighing $137 \mathrm{~g}$., were near average in weight. There was slight widening of the subarachnoid space and cerebral suki, but no abnormality was visible on slicing the fixed brain.

The heart, weighing $34 \mathrm{~g}$., and great vessels, were normal.

The trachea contained frothy, blood-stained fluid but showed no mucosal injection. The lungs, weighing $165 \mathrm{~g}$., were heavy owing to marked generalized oedema: they showed patchy collapse of both lower lobes and a few adhesions between the right lower lobe and the chest wall. Histologically there was mild interstitial pneumonia. Culture yielded profuse Esch. coli.

The stomach showed many mucosal erosions and there was much altered blood in the small intestine. Many adhesions bound the coils of small intestine to each other and to neighbouring structures and appeared responsible for a hair-pin bend in the terminal ileum, but there was no distension of the small intestine. The descending colon was small and empty, while the remainder of the colon was considerably distended by scybala.

The liver, weighing $228 \mathrm{~g}$., was congested; the spleen, weighing $27 \mathrm{~g}$., was normal; and the thymus was atrophic. The adrenals, weighing $2 \cdot 5 \mathrm{~g}$., were small and other organs were normal.

The diagnosis at necropsy was congestive heart failure complicating gastro-intestinal bleeding associated with cerebral degeneration.

Case 4. Born June 22, 1960, birth weight $2 \cdot 33 \mathrm{~kg}$., this boy was born when his brother, Case 3, was 2 years old and already physically and mentally retarded. He was a normal full-term infant born following a normal pregnancy and labour.

Progress was apparently normal up to about 5 months of age when his weight gain became slow and he developed a mucopurulent nasal discharge. He was severely constipated. He was able to lift his head, but made no attempt to sit up. His mother was convinced that he had the same disease as his brother.

On examination at 7 months of age he was found to weigh $5.65 \mathrm{~kg}$. (below the third percentile), although he did not appear poorly nourished. He had the large square head with prominent veins, the elfin face and the long digits observed in his brother. The abdomen was distended and scybala were felt in the descending colon. The head circumference and length were within normal limits. The baby appeared alert but could only just support his head and was unable to sit up. He continually made purposeless movements with his hands and did not grasp toys.

From the age of 7 months there was progressive mental and physical deterioration, persistent purulent nasal discharge and chronic constipation, with attacks of abdominal distension, frequently associated with high fever and dehydration. After the first year of life he did not have a spontaneous bowel action and deteriorated more rapidly, requiring institutional care. He died aged 1 year and 7 months.
At necropsy the body was undersized, underweight, and emaciated (Table 1) with the cranial and facial features already described. The abdomen was distended and the limbs wasted.

The brain, weighing 872 g., was small for the age, while the weight of medulla, pons, and cerebellum, $105 \mathrm{~g}$., was near average. There was slight widening of the subarachnoid space and of some of the cerebral suki. Slicing the fixed brain revealed considerable reduction in the volume of the central white matter and corpus callosum.

The heart, weighing $46 \mathrm{~g}$., and great vessels were normal. The trachea and larger bronchi were filled with thick mucopus. The lungs, weighing $258 \mathrm{~g}$., were bulky and emphysematous, with several areas of consolidation and collapse in all lobes. Histologically there was widespread bronchiolitis and bronchopneumonia. Cultures from lung and bronchial secretion yielded profuse Haem. influenzae.

The colon showed marked gaseous distension of the caecum and a segment of the transverse colon, and distension of the sigmoid by scybalae. The intervening segments were average or small in calibre. The liver, weighing $346 \mathrm{~g}$., was congested. The gall-bladder was normal.

The spleen, weighing $50 \mathrm{~g}$., was slightly enlarged, and the mediastinal and mesenteric lymph nodes were moderately enlarged; the thymus, weighing $2 \mathrm{~g}$., was atrophic; and the adrenals, weighing $2.5 \mathrm{~g}$., were small.

The bones were slightly yellow (obvious only after stripping the periosteum) and fluoresced in ultraviolet light (Hilton, 1962). Teeth: all eight incisors had erupted and all were yellow near the gum margin. A section of one of the teeth showed two thin yellow lines in the dentine, corresponding with two courses of tetracycline given when the baby was 10 and 13 months old (Wallman and Hilton, 1962).

The diagnosis at necropsy was purulent bronchitis and broncho-pneumonia complicating cerebral degeneration.

\section{Summary of Clinical and Necropsy Findings}

Clinical Features. Failure to develop physically and mentally after an apparently normal start in life, varying from a few months to a year or more, was common to all four children. Physical and mental deterioration set in during the few months before death.

Severe constipation, with attacks of vomiting and abdominal pain and distension, was present in all four children. One child (Case 3) developed intestinal obstruction associated with a gangrenous segment of ileum requiring resection, but continued to have attacks of abdominal distension. This child had a grossly distended colon at laparotomy, and another child (Case 2) was shown to have megacolon by barium enema.

Recurrent fits developed in three children (Cases 1, 2 and 3), and one boy (Case 2) died in status epilepticus.

A peculiar facies, with flat features, big ears, and a square head was present in the two brothers (Cases 3 and 4). They could possibly be described as elfin. The facies of the two children in the other family (Cases 1 and 2) were flat, inexpressive, and vacant, but not particularly characteristic. 
Apart from epileptic attacks, neurological signs were not a feature of any of the children. All four were hypotonic. One child (Case 1) was unsteady on her feet and another (Case 4) made purposeless movements with his hands.

Paroxysmal tachycardia developed in one child (Case 2) when he was 5 weeks old: he recovered rapidly after treatment with digoxin.

Investigations. These were mainly negative.

Cerebrospinal Fluid. Case 1 had normal fluid on three occasions (protein: 18, 20 and $30 \mathrm{mg} .100 \mathrm{ml}$.). Case 4 had no increase in cells but a raised protein on two occasions (150 and $50 \mathrm{mg}$./100 ml.). No examination was made in Cases 2 and 3.

Electroencephalogram. This was diffusely abnormal in Case 1 and normal in Case 2. The investigation was not done in Cases 3 and 4.

Urine. Metachromatic bodies were found in Case 4 but not looked for in the other cases. There was no increase in total urinary amino acids by chromatography in any of the four children, although in Case 4 glutamic acid, lysine, and tyrosine were detected three weeks before death.

Serum electrolytes, calcium, inorganic phosphates, and protein by electrophoresis were normal except that Cases 1 and 3 had low sodium values during attacks of vomiting with abdominal pain and distension.

Necropsy Findings. The bodies were all considerably undersized and even more underweight for the ages (Table 1).

Brains. The brains were also underweight for the ages (Table 1) and in Cases 2, 3, and 4 showed evidence of shrinkage due to reduction in the volume of the white matter of the cerebrum.

The heart of Case 2 was hypertrophied without anatomical abnormality. This was the patient who had paroxysmal tachycardia at 5 weeks.

The lungs showed generalized oedema (Cases 1, 2, and 3) and lobular collapse posteriorly in all four cases.

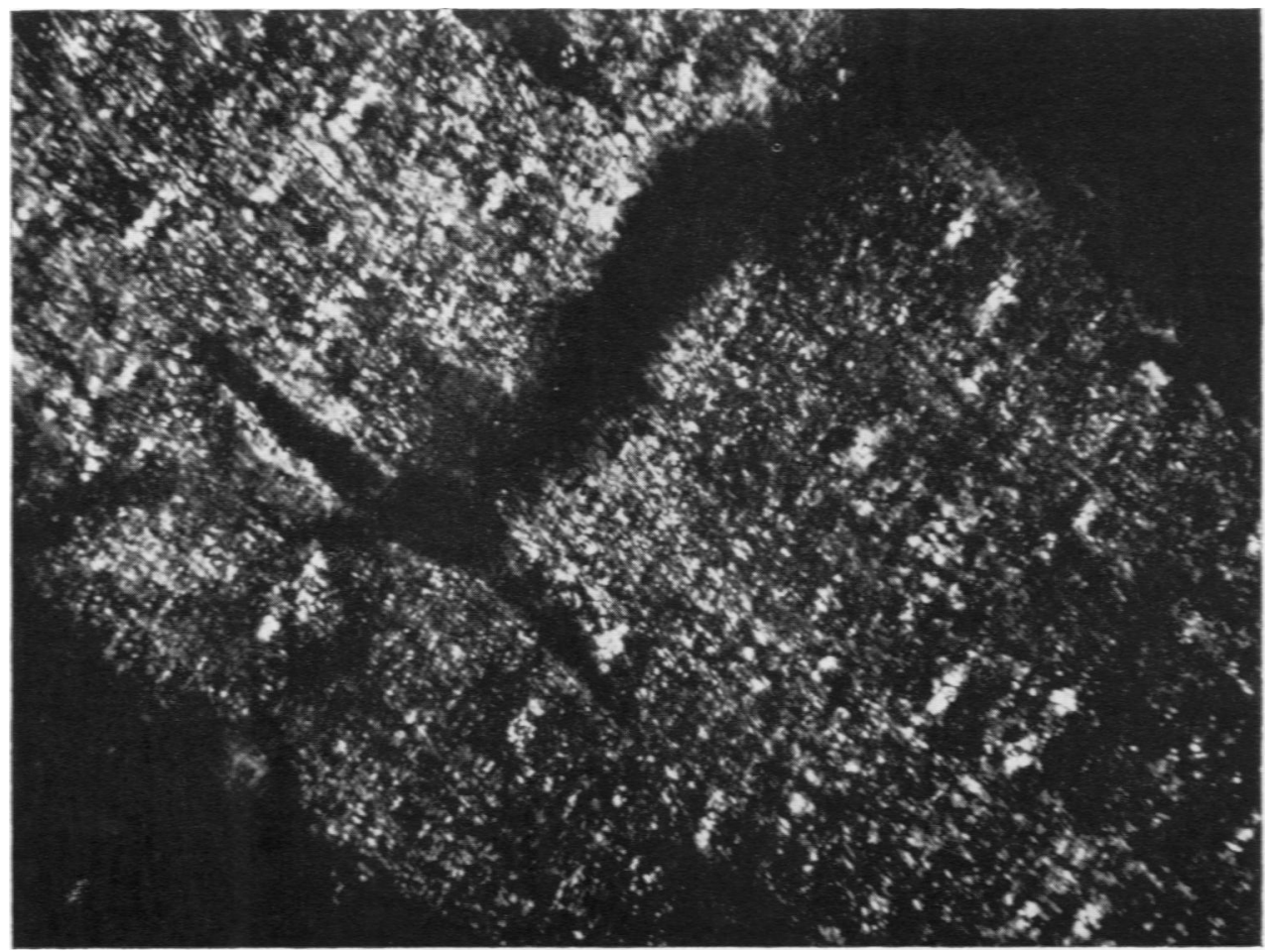

Fig. 1.-Case 2. Fibres of the pyramidal tract in corpus striatum showing doubly refractile deposits (unstained frozen section mounted in glycerol and viewed through crossed Nicols $\times 160$ ). 
The intestines from all four cases showed distended and contracted segments.

The adrenals of the patients in the second family (Cases 3 and 4) were small.

Histological Findings. Features common to children of both families were found in the brain, kidneys, and testes.

Brain. The appearances of brain sections embedded in paraffin were not dramatic. In some fibre tracts, especially the pyramidal tracts and medial leminisci in the medulla, there was a slight increase in glial fibres and a reduction in oligodendroglial cells. There was no eviderice of demyelination. In the cerebellum of Case 1 a considerable area of cortex and subcortical white matter showed necrosis of cells and a skeleton of glial fibres. A few necrotic Purkinje cells showed ferruginization. The appearances suggested long-standing ischaemic necrosis.

In the brains of Cases 2 and 3 numerous small, metachromatic and doubly refractile deposits about $10-50 \mu$ in diameter were visible in several fibre tracts: the pyramidal tracts in the brain-stem and corpus striatum, the medial leminisci, optic tracts and radiations, subcortical white matter of the cerebellum and more sparsely in the subcortical and paraventricular white matter of the cerebrum (Fig. 1). In paraffin-embedded sections these deposits were irregular and best demonstrated with toluidine blue which stained them purple. Alcian blue stained them a clear light blue, and luxol-fast blue failed to stain them. In frozen sections the deposits were round in ordinary light but irregular under crossed Nicol prisms. They stained pink with toluidine blue and cresyl violet and failed to stain with oil red, the periodic acidSchiff technique or luxol-fast blue (Figs. 2 and 3). Most of the deposits appeared to be extracellular. Deposits were not found in sections of brain from Cases 1 and 4, although unembedded material from the brain of Case 1 was not available.

Kidneys. The kidneys of Cases 2 and 4 showed evidence of chronic pyelonephritis: collections of lymphocytes and histiocytes in the cortex and pelvic connective tissue, dilated tubules containing casts, and fibrosed glomeruli. In the kidney of Case 3 there were foci of lymphocytes and histiocytes in the pelvic connective tissue suggesting pyelonephritis. In this child examination of a specimen of urine 17 months before death showed 1,400 leucocytes $/$ c.mm. and a profuse growth of Proteus and Esch. coli.

The kidneys of Cases 1, 2, and 3 showed small collections of vacuolated material. This was found mainly between the convoluted tubules but also distended the cytoplasm of scattered tubular epithelial cells. These deposits were usually close to glomeruli and often associated with casts in adjacent tubules (Fig. 4). In paraffin sections they stained purple with haematoxylin and eosin, pale purple to red with Mallory's trichrome, and red with periodic acid-Schiff. Some deposits also stained positively with alcian blue and mucicarmine. In frozen sections (available in Cases 2 and 3) the deposits stained purple with toluidine blue. They were not stained by luxol-fast blue in paraffin or frozen sections. In Case 4 one similar deposit was found in the medulla after search of several sections. The casts stained similarly to the deposits except that in frozen sections they stained light blue and not metachromatically with toluidine blue.

Testes. The testes of one patient in each family (Cases 2 and 3) showed an excess of interstitial tissue.

Apart from these changes in brain, kidney, and testis, which were found in both families, Cases 3 and 4 shared another histological feature. Sections from the apex of the right lung of both showed considerable areas of chronic inflammation. The bronchioles and alveolar ducts were irregularly dilated. Their walls were thickened by infiltration with plasma cells, lymphocytes, and macrophages, some of them multinucleate, and showed patchy fibrosis. Within the alveoli were neutrophils, red cells, and macrophages. Many of the macrophages contained granules positive for iron. In both cases these areas of chronic inflammation contained scanty oval objects about $150 \times 100 \mu$, staining palely with Mallory's trichrome technique. They contained irregular refractile structures showing up faintly under crossed Nicol prisms and strongly periodic acid-Schiff positive. These objects are believed to be inhaled and partially digested vegetable cells (Crome and Valentine, 1962).

Sections of colon from all four cases and of heart from Case 2 were examined for changes in the autonomic nerve plexuses. The examination included frozen sections stained with toluidine blue and cresyl violet. No abnormalities were detected in either nerve cells or nerve fibres.

\section{Biochemical Studies}

In view of the finding of metachromatic deposits in the brains of Cases 2 and 3, portions of these brains, a piece of brain from Case 4, and a piece of kidney from Case 2 were examined by one of us (J.N.C.), the provisional clinical and histological diagnosis being metachromatic leucodystrophy.

Technical Details. The water content was obtained after drying to constant weight in vacuo at $37^{\circ} \mathrm{C}$. Lipid extracts were prepared according to the technique of Folch, Lees, and Sloane Stanley (1957) using a $2: 1$ chloroform-methanol (v/v) solvent mixture. The methods used for the various estimations were: total phospholipid, total and free cholesterol (Cumings, 1953), hexosamine (Cumings, 1957), neutral cerebrosides (Radin, Lavin and Brown, 1955), sulphatides (Radin, Martin and Brown, 1957) gravimetrically and also by the resorcinol colorimetric method of hexose determination. Neuraminic acid was estimated by following the extractive procedures of Long and Staples (1959) and using the colorimetric technique of Svennerholm (1957).

Thin layer chromatography was employed using the same methods as in previous studies (Müldner, Wherrett and Cumings, 1962; Wherrett and Cumings, 1963).

Results. In Table 2 are given the results of the examinations of the portions of brain from Cases 2, 3, and 4 . 


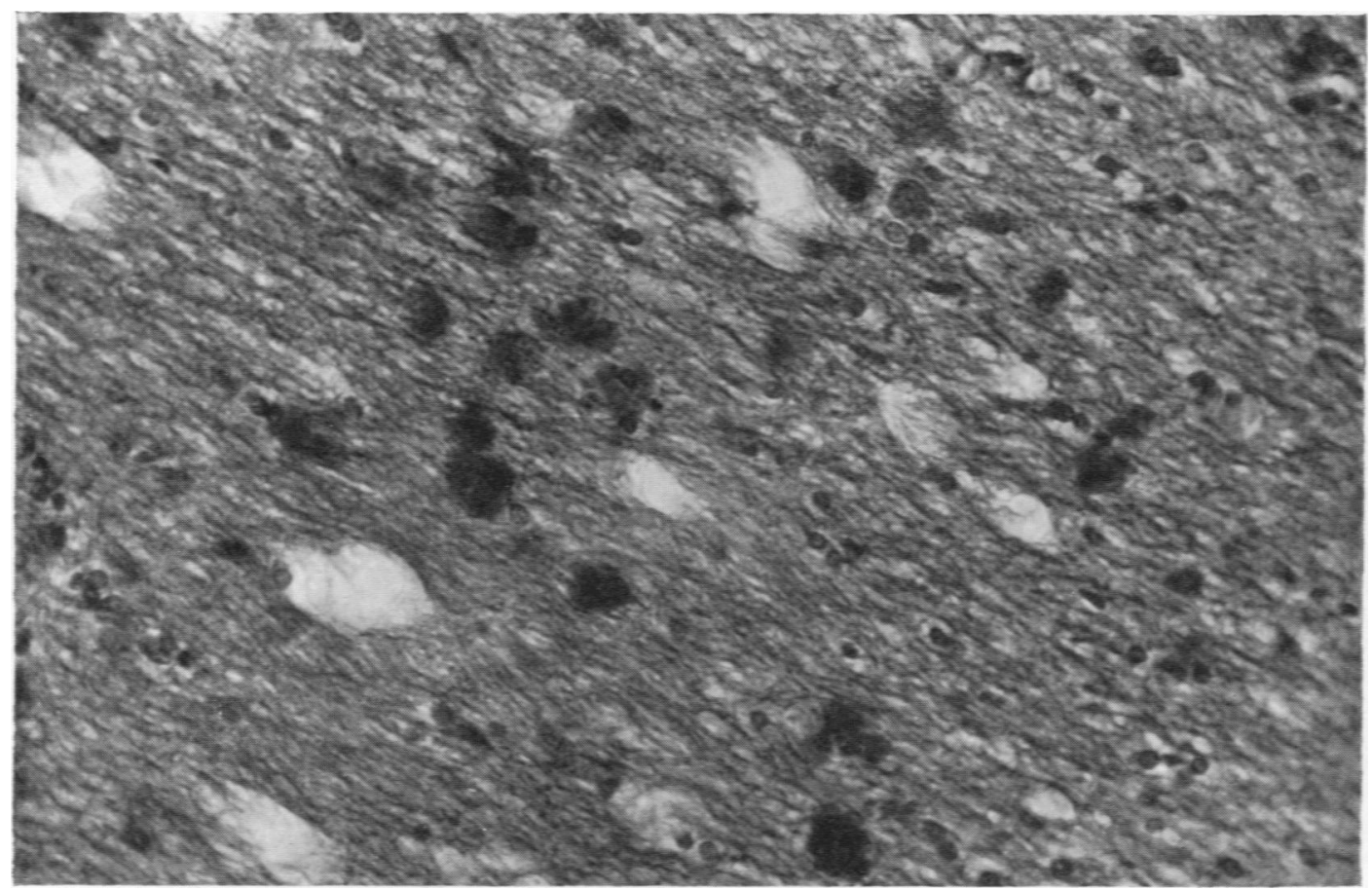

FiG. 2. Case 2. Optic tract showing metachromatic deposits (frozen section stained with toluidine blue $\times$ 582). Compare with Fig. 3.

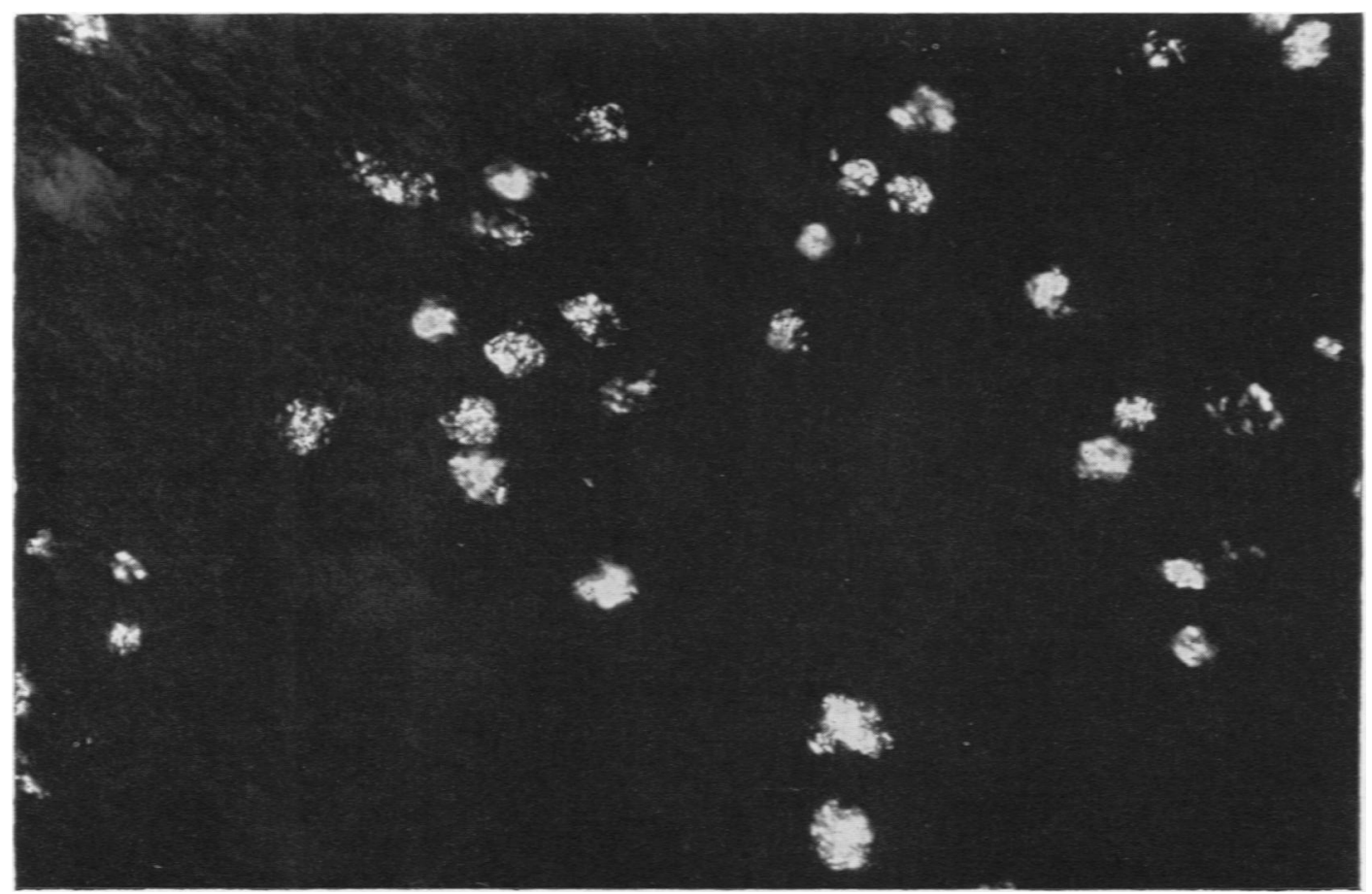

Fig. 3. - Case 2. Same field as Fig. 2 viewed through crossed Nicols. 


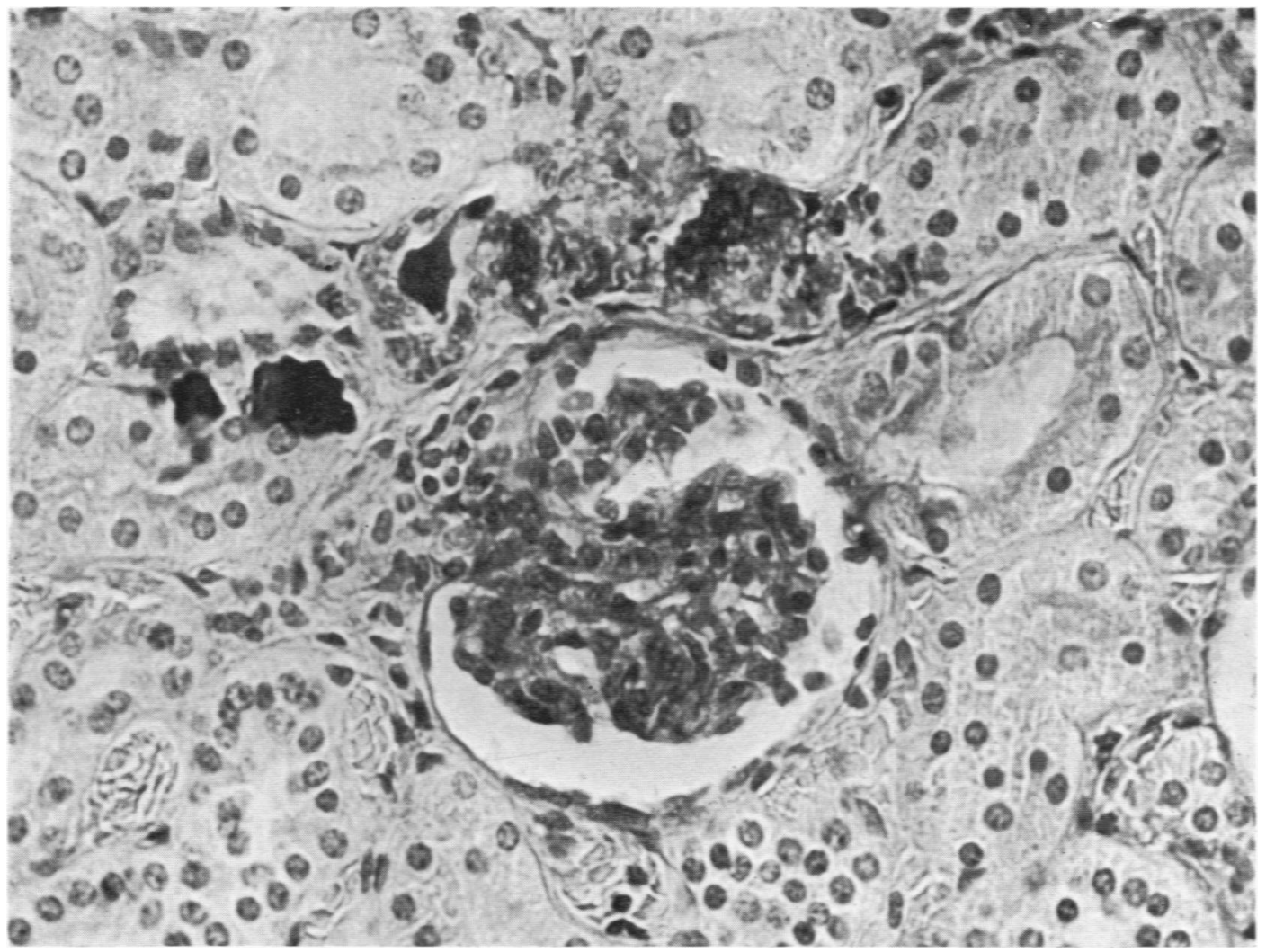

FKG. 4.-Case 3. Kidney showing foamy interstitial deposit above glomerulus and two PAS-positive casts (PAS $\times 454)$.

The normal lipid values for cerebral white matter and cortex at 2 to 3 years of age are given for comparison.

The results on the two brothers (Cases 3 and 4) show in the younger one only a very slight loss of phospholipid and cholesterol, but with no significant amount of esterified cholesterol in either white matter or cortex. However the cerebroside levels in the white matter and cortex are within the normal range, while both sulphatides and total hexosamine are raised above the normal in the white matter. The neuraminic acid content is normal.
Abnormalities are present in the lipids in the older brother for there is a considerable loss of phospholipids in the white matter, while in the cortex there is a very marked lowering of the level of total phospholipid and of cholesterol. Sulphatides in the white matter are somewhat increased with a normal cerebroside level, and total hexosamine is also almost normal.

In brain from Case 2 there is a gross loss of total phospholipids and a loss of cholesterol in both white matter and cortex, but there is no significant amount of

TABLE 2

RESULTS IN g. 100 g. DRY TISSUE

\begin{tabular}{|c|c|c|c|c|c|c|c|c|c|c|}
\hline \multirow{2}{*}{\multicolumn{2}{|c|}{ Substance }} & & \multicolumn{4}{|c|}{ Cerebral White Matter } & \multicolumn{4}{|c|}{ Cerebral Cortex } \\
\hline & & & $\begin{array}{l}\text { Normal } \\
(2-3 \text { yr. })\end{array}$ & $\begin{array}{c}\text { Case } 2 \\
2 \text { yr. } 10 \text { mth. }\end{array}$ & $\begin{array}{c}\text { Case } 3 \\
3 \text { yr. } 4 \mathrm{mth} .\end{array}$ & $\begin{array}{c}\text { Case } 4 \\
1 \mathrm{yr} .7 \mathrm{mth} .\end{array}$ & $\underset{(2-3 \text { yr. })}{\text { Normal }}$ & $\begin{array}{c}\text { Case } 2 \\
2 \mathrm{yr} .10 \mathrm{mth} .\end{array}$ & $\begin{array}{c}\text { Case } 3 \\
3 \mathrm{yr} .4 \mathrm{mth} .\end{array}$ & $\begin{array}{c}\text { Case } 4 \\
1 \mathrm{yr} .7 \mathrm{mth}\end{array}$ \\
\hline $\begin{array}{l}\text { Total phospholipid } \\
\text { Total cholesterol } \\
\text { Esterified cholestero } \\
\text { Neutral cerebrosides } \\
\text { Sulphatides . . } \\
\text { Total hexosamine } \\
\text { Neuraminic acid } \\
\text { Water }\left(\bullet^{\prime}\right) \text {.. }\end{array}$ & $\begin{array}{l}\cdots \\
\text { ol } \\
\text { es } \\
\cdots \\
\cdots\end{array}$ & $\begin{array}{l}\cdots \\
\cdots \\
\cdots \\
\cdots \\
\cdots \\
\cdots\end{array}$ & $\begin{array}{c}22-24 \\
12-14 \\
0 \cdot 4 \\
8-10 \\
1 \cdot 9 \\
0 \cdot 3 \\
74-77\end{array}$ & $\begin{array}{r}11 \cdot 6 \\
8 \cdot 6 \\
0 \cdot 4 \\
9 \cdot 2 \\
1 \cdot 4 \\
0 \cdot 2 \\
72 \cdot 0\end{array}$ & $\begin{array}{r}17 \cdot 7 \\
11 \cdot 8 \\
0 \cdot 4 \\
8 \cdot 9 \\
2 \cdot 6 \\
0 \cdot 3 \\
68 \cdot 3\end{array}$ & $\begin{array}{r}21 \cdot 8 \\
10 \cdot 9 \\
0 \cdot 5 \\
9 \cdot 0 \\
6 \cdot 5 \\
0 \cdot 6 \\
84 \cdot 9\end{array}$ & $\begin{array}{c}18-21 \\
6-8 \\
0 \\
2-4 \\
-\overline{0}-7 \\
0 \cdot 3 \\
82-85\end{array}$ & $\begin{array}{c}7 \cdot 6 \\
2 \cdot 3 \\
0 \\
2 \cdot 0 \\
\overline{0 \cdot 4} \\
0 \cdot 2 \\
82 \cdot 7\end{array}$ & $\begin{array}{c}11 \cdot 3 \\
5 \cdot 8 \\
0 \\
3 \cdot 5 \\
-\overline{0 \cdot 5} \\
0 \cdot 2 \\
80 \cdot 6\end{array}$ & $\begin{array}{r}21 \cdot 5 \\
7 \cdot 8 \\
0 \cdot 2 \\
2 \cdot 3 \\
\overline{0 \cdot 7} \\
0 \cdot 2 \\
85 \cdot 5\end{array}$ \\
\hline
\end{tabular}




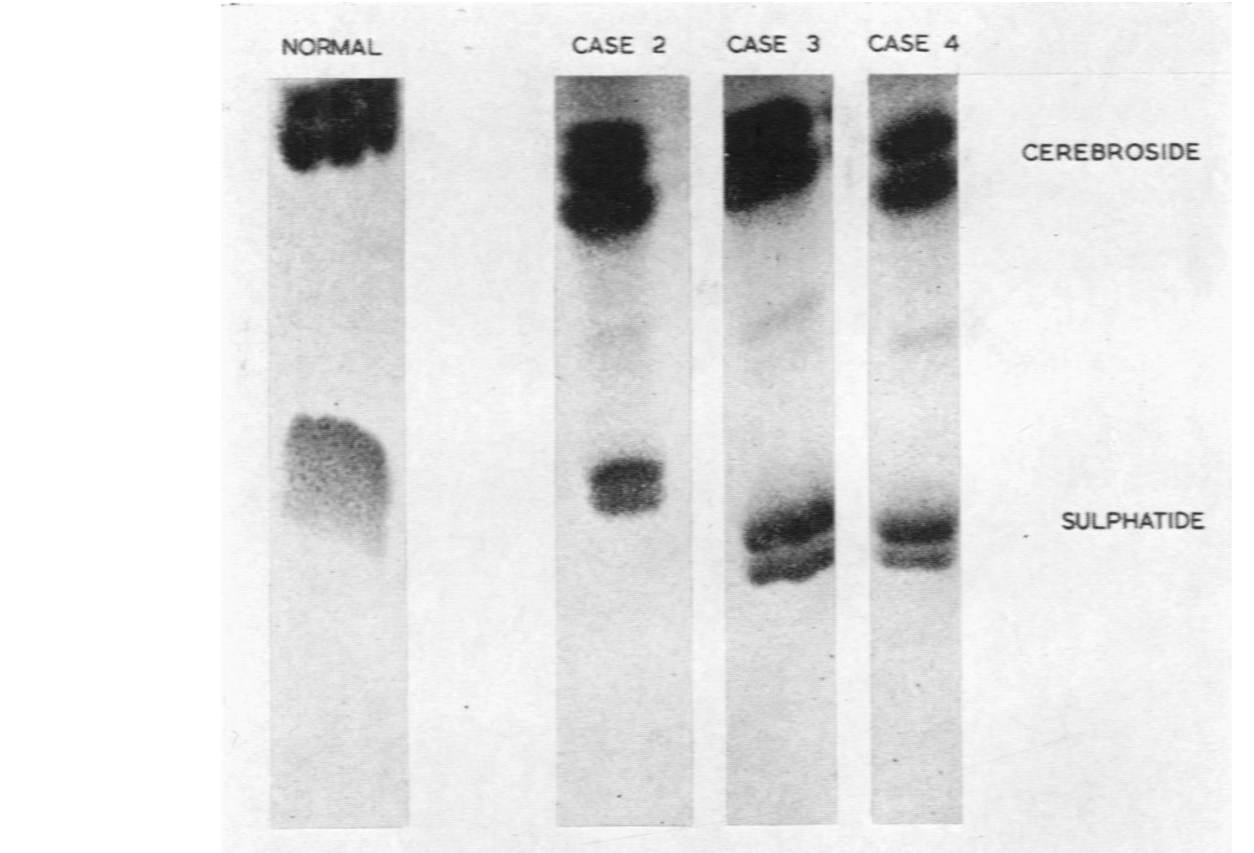

FIG. 5.-Thin-layer chromatography of lipids to show cerebrosides and sulphatides of the cerebral white matter after florisil treatment. Solvent : chloroform-methanol-water (14:6:1, by vol.). Detection : molybdate-perchloric acid.

esterified cholesterol present. Cerebrosides and gangliosides are both normal in amount. The levels of sulphatide and total hexosamine are within the normal range for the age. Portions of the kidney of this case showed only a small and normal amount of sulphatide.

Thin layer chromatography of lipid extracts of white matter (as seen in Fig. 5) shows a slight increase of sulphatide relative to cerebroside as compared to normal in Case 4, but no striking increase in the older brother (Case 3). However the cerebral material was formol fixed, and this renders the results in this examination more difficult to interpret than when fresh tissue is used. Kidney tissue from Case 2 showed no appreciable sulphatide in thin-layer chromatography and practically negligible amounts of hexosamine were present in the estimations.

\section{Discussion}

The biochemical findings in the brains of the two families showed important differences.

The results obtained in Case 2 show a gross loss of all lipids, indicating a marked disturbance of myelination. However, the lipid analysis shows no specific diagnostic feature and no evidence of metachromatic leucodystrophy.

The findings in the two brothers (Cases 3 and 4) would be compatible with a diagnosis of metachrom- atic leucodystrophy. The younger boy shows relatively little change in the lipids apart from the altered sulphatide cerebroside ratio and the increased amount of the former substance. In this connexion these observations are comparable with those found in other reports (Austin, 1960; Hagberg, Sourander, Svennerholm and Voss, 1960; Black and Cumings, 1961 ; Mossakowski, Mathieson and Cumings, 1961). The older brother in whom the disease was of longer standing shows a loss of all lipids especially marked in the cortex. Though the total phospholipid level has been reduced in amount, sulphatides are maintained or even slightly increased. This has been seen previously by one of us (J.N.C.) in other cases living for some time.

It is generally agreed now that in metachromatic leucodystrophy there is an increased amount of sulphatide in the white matter, and Cases 3 and 4 show this feature. Further in almost every case, as originally suggested by Edgar (1957), there is a raised hexosamine content, and this was present in Case 4. Whether metachromatic leucodystrophy can occur without either of these features is doubtful.

In relation to the histological findings the chemical findings appear paradoxical. The brain of Case 4 showed the two special chemical features of meta- 
chromatic leucodystrophy (MLD), a raised sulphatide and hexosamine content of the white matter, but no metachromatic deposits. The brain of his brother, Case 3, showed a raised sulphatide in the white matter, and metachromatic deposits were present. The brain of Case 2 showed no increase in either substance in the white matter, but metachromatic deposits were as plentiful as in the brain of Case 3.

On review it became clear that our cases lacked several histological features commonly found in MLD. In MLD there is usually histological evidence of demyelination (Norman, 1947; Brain and Greenfield, 1950; Leslie, 1952): this was absent in our cases. In addition the metachromatic material is characteristically brown when stained with cresyl violet (von Hirsch and Peiffer, 1957; Diezel, 1960): in our cases the metachromatic material stained pink with cresyl violet.

As well as being present as deposits in the white matter, the metachromatic material has usually been found in various other sites: macrophages in the white matter, nerve cells, especially in the dentate nucleus, peripheral nerves, macrophages in the gallbladder and portal tracts, and the renal tubular epithelium (Norman, 1947; Brain and Greenfield, 1950: Hagberg, Sourander and Svennerholm, 1962a).

On the basis of the deposits in peripheral nerves and myenteric plexuses, Hagberg, Sourander and Thorén (1962b) recommended sural nerve biopsy, and Martin, Landing and Nakai (1963) recommended rectal biopsy as diagnostic tests for MLD. In our cases metachromatic deposits outside the central nervous system appeared to be confined to the kidneys where they were scanty and mainly interstitial.

Metachromatic bodies in the urine, present in Case 4, were considered by Austin (1957) to be diagnostic of MLD. Hagberg and Svennerholm (1959) found that metachromatic bodies were excreted in the urine of normal babies and showed chromatographically that they were sulphate esters of cerebrosides (sulphatides). They found that the quantity of sulphatide excreted in the urine is 5 to 10 times more in children with MLD than in normal children of the same age. Hagberg et al. (1962a) have described a quantitative method for determining sulphatides in urine by chromatography and consider that this will provide a definitive diagnosis. Chromatography of urine from our patients was confined to amino acids. No special significance is attached to the finding of glutamic acid, tyrosine, and lysine in urine from Case 4 who was then very weak and died three weeks later.

The significance of the metachromatic deposits found in the brains and kidneys of Cases 2 and 3 has been investigated by examining frozen sections stained by toluidine blue from the brain-stems and kidneys of 20 routine necropsies: 3 brain-stems showed profuse or moderate numbers of metachromatic deposits and 8 showed scanty deposits. These deposits closely resembled those found in Cases 2 and 3 in size, staining reactions, and birefringence. Other histological evidence of brain pathology was confined to 3 out of the 11 cases showing deposits: a 3-year-old girl with pharyngeal diphtheria who was comatose for three weeks before death owing to a severe anoxic episode (profuse deposits), a 10-year-old girl who died from medulloblastoma of the medulla, pons, and cerebellum (scanty deposits), and a 6-month-old hydrocephalic infant with thrombi in the corpus striatum and intracranial sinuses (scanty deposits). The frequency of finding metachromatic deposits of this kind in the brain-stem indicates that they are not specific for chronic brain pathology: they appear to be similar to the metachromatic bodies described by Smith (1949).

Renal deposits were found in only 2 of the 20 necropsies, and again they resembled closely those in Cases 1, 2, and 3, in both morphology and staining reactions. One of the cases showing renal deposits was the child who died from medulloblastoma of the medulla, pons, and cerebellum. The extensive destruction of brain substance that had taken place in this child supports the hypothesis that the renal deposits found in our cases were secondary to brain pathology. The other child showing renal deposits died at the age of 6 months following relapsing enteritis beginning ten weeks before death. Complications included abscess formation at a site of intravenous therapy and, terminally, respiratory infection and renal vein thrombosis. There was no clinical or histological evidence of chronic brain pathology.

Although our cases showed similar clinical and histological features, the chemical evidence is that there were different disorders of white matter in the two families. The main histological feature in the brain linking the two families, i.e. the presence of metachromatic deposits, is non-specific. The other histological feature common to the two families, i.e. the renal deposits, also appears to be non-specific, although it may indicate chronic brain pathology. Case 4 illustrates that absence of histological change does not exclude chemical changes in the brain.

On the chemical evidence we consider that our cases belong to the leucodystrophies or dysmyelinating group of diffuse cerebral sclerosis (Poser, 1960). We suggest that Cases 3 and 4 suffered from a variant of metachromatic leucodystrophy. The published material shows that the histological features of this 
disease are variable: Zeman and Whieldon (1962) comment that "owing to the complexity of myelin metabolism it is not unreasonable to assume that future research will uncover a greater variety of leucodystrophies than are currently known. The literature already contains a fair number of cases which do not fit in the established categories'.

The chemical differences between the two families may reflect defects in different enzymes, each concerned with a stage in the metabolism of myelin, just as the enzymes deficient in congenital adrenal hyperplasia are concerned with various stages in the metabolism of the adrenocortical steroids. Zeman and Whieldon (1962) further comment that it is important to remember that the leucodystrophies are genetically controlled disorders and therefore may show considerable fluctuations of clinical and pathological features from one family to another; however, all the cases occurring within the same family usually exhibit a fair degree of similarity'.

Bowel dysfunction, sufficiently serious in two children (Cases 2 and 3) to suggest Hirschsprung's disease, was a prominent feature in our patients and, as far as we know, has not hitherto been reported as a feature of leucodystrophies. One of our patients had paroxysmal tachycardia in early infancy and showed cardiomegaly at necropsy, as well as considerable distension of segments of the ileum and colon. The combination of cardiomegaly and megacolon is similar to that found in Chagas' disease (Ferreira-Santos, 1961), in which there is trypanosomal damage to the autonomic plexuses in the viscera, and supports the theory that the autonomic nervous system was damaged in our patients. The studies on our patients support the view that further progress in the understanding of the causes of familial mental deterioration in childhood is dependent on refined and detailed chemical analyses.

\section{Summary}

This paper has described the clinical, histological, and biochemical features of four small children in two families suffering from progressive physical and mental deterioration after a few months of normal development. Their clinical features, which were remarkably similar, were in keeping with a diagnosis of metachromatic leucodystrophy but included megacolon associated with attacks of abdominal distension. Metachromatic deposits were present in two of the brains but their nature was not characteristic of metachromatic leucodystrophy. Chemical evidence favouring the diagnosis of metachromatic leucodystrophy was found in the two patients in one family but not in a patient from the other family. We suggest that our patients belong to a group of disorders that includes metachromatic leucodystrophy, in which the common factor is an inborn disturbance of myelin metabolism. Chemical and other differences between the brains in different families are assumed to be due to specific biochemical defects affecting different stages in the metabolism of myelin.

\section{REFERENCES}

Austin. J. H. (1957). Metachromatic form of diffuse cerebral sclerosis: I. Diagnosis during life by urine sediment examination. Neurology (Minneap.). 7. 415.

- (1960). Metachromatic form of diffuse cerebral sclerosis: III. Significance of sulfatide and other lipid abnormalities in white matter and kidney. ibid., $10,470$.

Black, J. W. and Cumings, J. N. (1961). Infantile metachromatic leucodystrophy. J. Neurol. Neurosurg. Psychiat.. 24, 233.

Brain, W. R. and Greenfield. J. G. (1950). Late infantile metachromatic leuco-encephalopathy with primary degeneration of the interfascicular oligodendroglia. Brain. 73. 291.

Crome, L. and Valentine. J. C. (1962). Pulmonary nodular granulomatosis caused by inhaled vegetable particles. J. clin. Path., 15, 21.

Cumings, J. N. (1953). The cerebral lipids in disseminated sclerosis and in amaurotic family idiocy. Brain. 76. 551.

- (1957). The diagnostic value of lipid estimations in the cerebral lipidoses. In Cerebral Lipidoses: A Symposium. ed. L. van Bogaert. J. N. Cumings and A. Lowenthal, p. 112. Blackwell Scientific Publications. Oxford.

_ (1962). Metachromatic leucodystrophy: Some biochemical observations. In Proceedings of the London Conference on the Scientific Study of Mental Deficiency. 1960, ed. B. W. Richards. Vol. 2. p. $449 . \quad$ May and Baker. London.

Diezel, P. B. (1960). Lipidoses of the central nervous system. In Modern Scientific Aspects of Neurology, ed. J. N. Cumings, p. 98. Arnold. London.

Edgar, G. W. F. (1957). Leuco-dystrophy as an inborn metabolic error'. comparable to lipidosis. In Cerebral Lipidoses: A Symposium, ed. L. van Bogaert. J. N. Cumings and A. Lowenthal. p. 186. Blackwell Scientific Publications, Oxford.

Ferreira-Santos, R. (1961). Megacolon and megarectum in Chagas' disease. Proc. roy. Soc. Med. 54. 1047.

Folch, J., Lees, M. and Sloane Stanky. G. H. (1957). A simple method for the isolation and purification of total lipides from animal tissues. J. biol. Chem., 226, 497.

Hagberg. B., Sourander, P. and Svennerholm. L. (1962a). Sulfatide lipoidosis in childhood. Amer. J. Dis. Child., 104. 644.

- - and Vess, H. (1960). Late infantile metachromatic leucodystrophy of the genetic type. Acta paediat. (Lppsala), 49, 135.

- and Thorén. L. (1962b). Peripheral nerve changes in the diagnosis of metachromatic leucodystrophy. ibid.. Suppl. 135, p. 63.

- and Svennerholm. L. (1959). Laboratory diagnostic tests in metachromatic leucodystrophy. ibid., 48, 632.

Hilton. H. B. (1962). Skeletal pigmentation due to tetracycline. J. clin. Path., 15. 112.

von Hirsch, T. and Peiffer. J. (1957). A histochemical study of the prelipid and metachromatic degenerative products in leucodystrophy. In Cerebral Lipidoses: 1 Symposium. ed. L. van Bogaert, J. N. Cumings and A. Lowenthal, p. 68 . Blackwell Scientific Publications, Oxford.

Jatzkewitz, H. (1960). Die Leukodystrophie. Typ Scholz, (metachromatische Form der diffusen Sklerose) als Sphingolipoidose (Cerebrosid-schwefelsäureester-Speicherkrankheit). Hoppe-Seylers Z. physiol. Chem.. 318, 265.

Leslie, D. A. (1952). Diffuse progressive metachromatic leucoencephalopathy. J. Path. Bact.. 64, 841.

Long. C. and Staples, D. A. (1959). Determination of neuraminic acid in crude brain lipids. Biochem. J.. 73. 385.

Martin. L. W.. Landing. B. H. and Nakai. H. (1963). Rectal biopsy as an aid in the diagnosis of diseases of infants and children. J. Pediat.. 62. 197. 
Mossakowski. M., Mathieson, G. and Cumings, J. N. (1961). On the relationship of metachromatic leucodystrophy and amaurotic idiocy. Brain. 84. 585.

Müldner, H. G., Wherrett. J. R. and Cumings, J. N. (1962). Some applications of thin-layer chromatography in the study of cerebral lipids. J. Neurochem.. 9, 607.

Norman. R. M. (1947). Diffuse progressive metachromatic leucoencephalopathy. Brair. 70. 234.

Poser. C. M. (1960). The differential diagnosis of diffuse sclerosis in children. Amer. J. Dis. Child., 100, 380.

Radin, N. S., Lavin. F. B. and Brown. J. R. (1955). Determination of cerebrosides. J. biol. Chem., 217, 789.

_- Martin, F. B. and Brown, J. R. (1957). Galactolipide metabolism. ibid., 224, 499.
Smith. M. C. (1949). Metachromatic bodies in the brain. J. Neurol. Neurosurg. Psychiat., 12, 100.

Svennerholm, L. (1957). The nature of the gangliosides in Tay-Sachs' disease. In Cerebral Lipidoses: A Symposium. ed. L. van Bogaert, J. N. Cumings and A. Lowenthal, p. 139. Blackwell Scientific Publications, Oxford.

Wallman, I. S. and Hilton, H. B. (1962). Teeth pigmented by tetracycline. Lancet. 1, 827.

Wherrett, J. R. and Cumings, J. N. (1963). Detection and resolution of gangliosides in lipid extracts by thin-layer chromatography. Biochem. J., 86, 378.

Zeman, W. and Whieldon, J. A. (1962). Clinical considerations in "Schilder's disease". Amer. J. Dis. Child., 104, 635. 